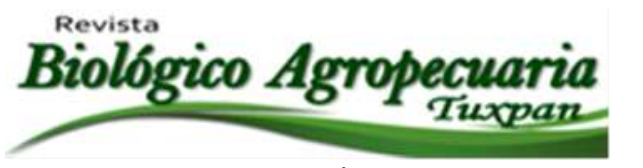

\title{
Evaluación de la capacidad antimutagénica de extractos etanólicos de Té verde (Camellia sinensis)
}

Evaluation of the antimutagenic capacity of ethanolic extracts of Green Tea (Camellia sinensis)

\author{
Hernández-Lozada Alejandra Sarahi ${ }^{1}$, Gaytán-Oyarzún Juan Carlos ${ }^{1}$, López-Herrera Maritza ${ }^{1}$ y Pablo \\ Octavio Aguilar ${ }^{1}$, Guzmán Ortiz Fabiola ${ }^{2}$ \\ ${ }^{1}$ Área Académica de Biología, Universidad Autónoma del Estado de Hidalgo, Pachuca, Hidalgo. ${ }^{2}$ Área \\ Académica de Química Universidad Autónoma del Estado de Hidalgo, Pachuca, Hidalgo.
}

${ }^{\square}$ Autor para correspondencia: jcgaytan@uaeh.edu.mx

Recibido: 05/09/2019

Aceptado: 19/11/2019

\section{RESUMEN}

En la actualidad, las plantas medicinales contienen principios activos, que si bien son los responsables de las propiedades terapéuticas que se les atribuyen, también lo son de las intoxicaciones y reacciones adversas que pueden aparecer si se emplean en dosis inadecuadas o por períodos prolongados. Por lo tanto, el objetivo del presente trabajo es evaluar la posible capacidad antimutágena del extracto etanólico de té verde (Camellia sinensis) sustentado en su alto contenido antioxidante reportado. Para ello, se determinó la actividad antimutagénica mediante la prueba de mutación y recombinación somática (SMART), con un tratamiento previo de extractos etanólicos de té verde y tratamiento subsecuente con un mutágeno de referencia (O-Toluidina), evaluando la inhibición de manchas o clones celulares en ojo de Drosophila melanogaster. En cuanto a los resultados, se observó que el extracto etanólico administrado previamente al mutágeno de referencia, inhibió de manera significativa el daño genotóxico, siendo más efectivo para manchas pequeñas que grandes. En general, los resultados sugirieron que los extractos de té verde evaluados, tienen propiedades biológicas con un potencial benéfico para la salud humana y que se pueden utilizar en tratamientos preventivos contra el cáncer o exposición relacionadas con mutágenos de manera laboral o naturales.

Palabras clave: Antioxidante, antimutágeno, fenoles, fitoquímicos.

\begin{abstract}
ABSTRAC
At present, medicinal plants contain active ingredients, which although they are responsible for the therapeutic properties attributed to them, they are also responsible for the poisonings and adverse reactions that may occur if they are used in inappropriate doses or for prolonged periods. Therefore, the objective of the present work is to evaluate the possible antimutagenic capacity of the ethanolic extract of green tea (Camellia sinensis) based on its high antioxidant content reported. To this end, the antimutagenic activity was determined by means of the mutation and somatic recombination test


(SMART), with a previous treatment of ethanolic extracts of green tea and subsequent treatment with a reference mutagen (O-Toluidine), evaluating the inhibition of spots or cell clones in the eye of Drosophila melanogaster. Regarding the results, it was observed that the ethanolic extract previously administered to the reference mutagen significantly inhibited genotoxic damage, being more effective for small than large spots. In general, the results suggested that the green tea extracts evaluated, have biological properties with a beneficial potential for human health and that can be used in preventive treatments against cancer or exposure related to mutagens in a work or natural way.

Keywords: Antioxidant, antimutagen, phenols, phytochemicals.

\section{INTRODUCCIÓN}

En la actualidad, hay un incremento en el consumo de bebidas a base de plantas medicinales debido a sus propiedades benéficas atribuidas a la presencia de compuestos fenólicos que podrían prevenir la mutaciones, procesos cancerígenos, enfermedades cardiovasculares o incluso de enfermedades neurodegenerativas como el Alzheimer (Gee y Johnson, 2001). Las plantas medicinales contienen principios activos, que si bien son los responsables de las propiedades terapéuticas que se les atribuyen, también lo son de las intoxicaciones $y$ reacciones adversas que pueden aparecer si se emplean en dosis inadecuadas o por períodos prolongados. Por lo tanto las plantas han sido una fuente de fitoquímicos útiles tanto en el tratamiento de enfermedades así como en su prevención (Figueroa y Lama, 2002).

Los antimutágenos naturales presentes en la dieta constituyen una opción importante como agentes quimiopreventivos contra el cáncer y otros padecimientos de riesgo, ya que la mayoría de los inhibidores sintéticos de la mutagénesis provenientes de otras fuentes pueden causar efectos adversos.

El té verde que se obtiene de la planta Camellia sinensis es altamente utilizado por la población, por su uso medicinal debido a su alto contenido de antioxidantes (Muñoz et al., 2012). Actualmente es un té con un rango de estudio amplio en cuanto a sus componentes, principalmente por su potencial aplicación contemporánea, sin embargo no hay suficientes registros que argumenten propiedades anticancerígenas y/o antimutágenas (Figueroa y Lama, 2002).

Hoy en día, las plantas son fuente directa de agentes químico-terapéuticos, que se emplean como materia prima para la fabricación de medicamentos semisintéticos más complejos, la estructura química de sus principios activos como los antioxidantes, fenoles, polifenoles, vitaminas, entre otros (Figura 1), puede servir de modelo para la elaboración de drogas sintéticas y se pueden prevenir la aparición de enfermedades hereditarias y procesos cancerígenos, así como marcadores taxonómicos en la búsqueda de nuevos medicamentos (Martí, 2004; García, 2008).

Se define como antioxidante a cualquier molécula capaz de prevenir o retardar la oxidación de otras moléculas (pérdida de uno o más electrones), lo que ocurre generalmente en sustratos biológicos como lípidos, proteínas o ácidos nucleicos. La oxidación de tales sustratos podrá ser iniciada por dos tipos de especies reactivas: los radicales libres y aquellas especies que sin ser radicales libres, son suficientemente reactivas para inducir la oxidación de sustratos 
Hernández-Lozada et al., 2019

como los mencionados (Patthamakanokporn et al., 2008; Nuñez, 2011).

Por lo tanto es necesario investigar las propiedades de estos compuestos para ampliar y validar su uso en la población y en el presente trabajo se evaluó el efecto antimutagénico de extractos etanólicos obtenidos de té verde (Figueroa y Lama, 2002).
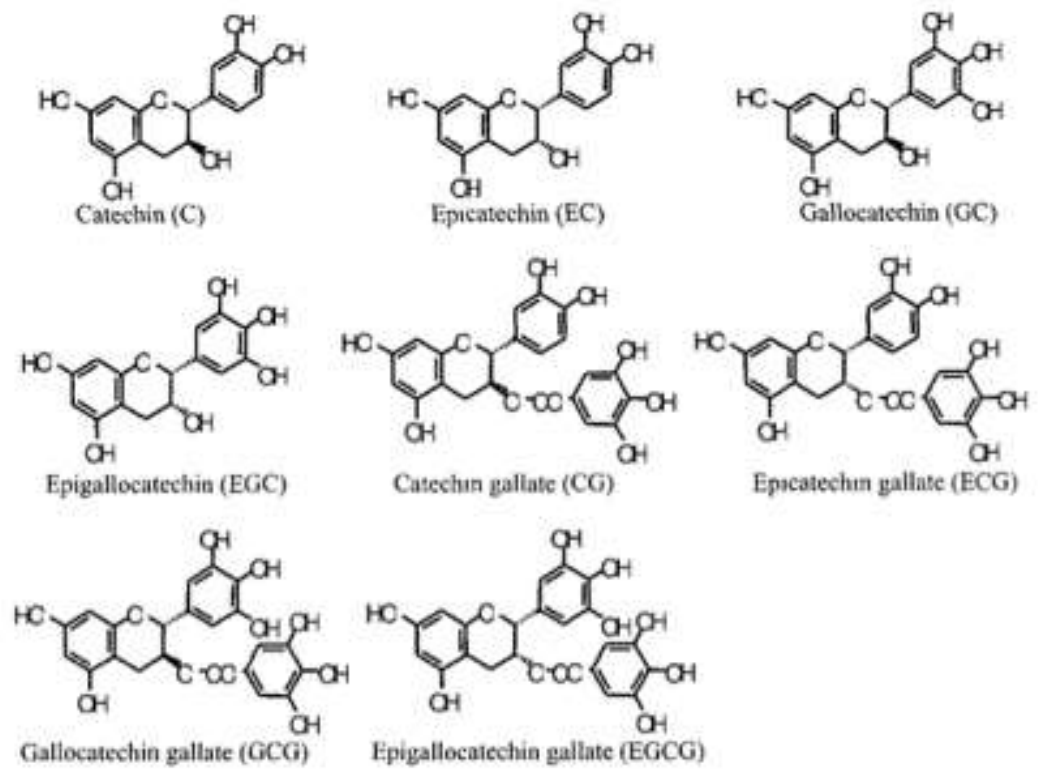

Figura 1. Estructura química de las catequinas y de los polifenoles que contiene C. sinensis (Gaur, 2013).

\section{MATERIALES Y MÉTODOS}

\section{Obtención de extractos etanólicos de té}

verde (C. sinensis).

Los extractos de té verde (marca Alessa) se obtuvieron con etanol absoluto, con el objetivo de arrastrar diversos tipos de principios activos, se tomó $2 \pm 0,01 \mathrm{~g}$ de té verde pulverizado (como se vende comercialmente), y se añadieron $10 \mathrm{ml}$ de solvente, posteriormente se colocó en agitación durante 18 horas en oscuridad, utilizando un agitador orbital, para favorecer la extracción de los principios activos; posteriormente se realizó una centrifugación durante 30 min a 5000 rpm., una vez centrifugado, se recuperó únicamente el sobrenadante, con el objetivo de eliminar los residuos sólidos de la planta (Figura 2); para la obtención de los extractos puros de té verde, se requirió eliminar el solvente (etanol absoluto), debido a que puede ser toxico para el organismo (D. melanogaster), para ello se colocaron 100 $\mathrm{ml}$ del extracto etanólico en un rotavapor a $40^{\circ} \mathrm{C}$ y 150 rpm hasta alcanzar la dilución 1/10, la cual se utilizó para las curvas de toxicidad y para la actividad antimutagénica . 


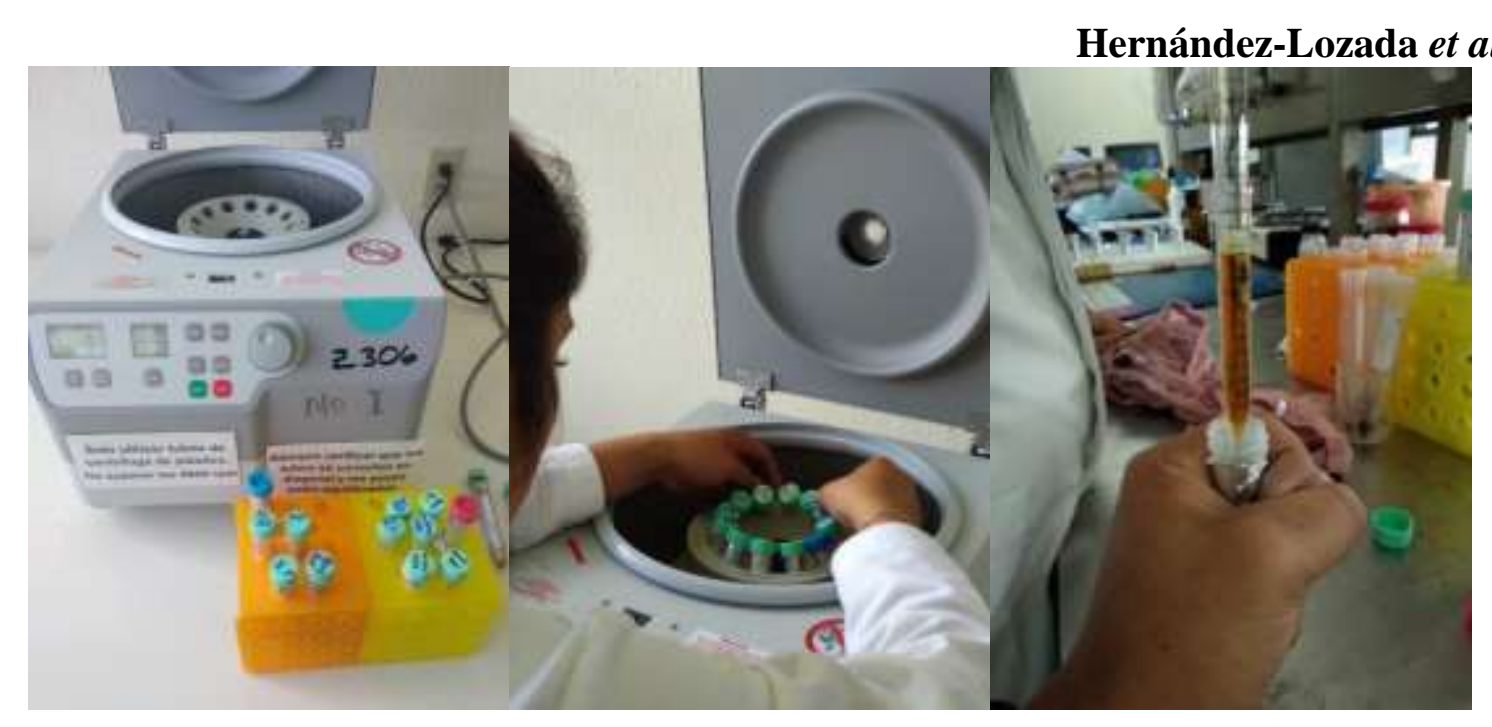

Figura 2. Centrifugación y recuperación del sobrenadante del extracto de la planta.

\section{Sistema de cruza.}

Se realizó una cruza entre hembras vírgenes de Drosophila melanogaster de ojos blancos (w/w) y machos de ojos rojos $(w+/ Y)$, en un medio de cultivo a una temperatura de $25 \pm 1^{\circ} \mathrm{C}$ y a una humedad relativa de $60 \%$. Con tres días de ser realizada la cruza, se retiraron los progenitores, obteniendo larvas heterocigóticas $(\mathrm{w}+/ \mathrm{w})$ de 72 horas de edad.

\section{Curvas de toxicidad}

Este procedimiento es para la selección de concentraciones toxicas y subtóxicas a partir de la Concentración Letal 50 (CL50) (Alba, 1999), se realizó:

1. Control negativo (sacarosa al 5\%).

2. Mutágeno de referencia (O-Toluidina) a $2 \mathrm{mM}$.

3. Extracto etanólico de té verde, a varias concentraciones que permitan determinar la CL50 y dos concentraciones subtóxicas.

Para estas evaluaciones se utilizaron larvas de 72 horas de edad correspondientes a la cepa White en heterocigosis $(\mathrm{w}+/ \mathrm{w})$, separadas a través de un gradiente con sacarosa al $60 \%$ (Gaytán, 2006); colocando las larvas en un vial con sacarosa y $2 \mathrm{ml}$ del extracto durante 24 horas, al término de este periodo, se evaluó el índice de mortalidad a través del número de pupas eclosionadas y no eclosionadas (Gaytán, 2006). Eligiendo la dosis letal 50 (LD50) como concentración máxima experimental, y dos más subtóxicas que corresponde a la mitad de la primer y a la mitad de la segunda, estableciendo las concentraciones de $12.5 \%, 25 \%$ y $50 \%$, para té verde.

\section{Tratamiento mutagénico y antimutagénico.}

Para la realización del tratamiento experimental, con de O-Toluidina 2mM. Se utilizaron larvas de 72 horas de edad (Gaytán, 2006).

1. Tratamiento mutagénico, consistió en una exposición vía alimenticia con sacarosa al 5\% (control negativo), durante un tiempo de 24 horas y un segundo tratamiento con el mutágeno de referencia O-Toluidina (control positivo) durante un tiempo de 24 horas y un tercer tratamiento con extractos puros de té verde recién preparados (Gaytán, 2006).

2. Tratamiento antimutagénico, consistió en una exposición vía alimenticia con sacarosa al 5\% (control negativo), y un segundo tratamiento mixto, el cual consistió en un tratamiento vía alimenticia con el extracto etanólico de té verde en las diferentes diluciones por 
Hernández-Lozada et al., 2019

separado durante un tiempo de 12 horas, posteriormente un tratamiento con el mutágeno de referencia O-Toluidina (control positivo) durante12 horas más.

En todos los tratamientos, al finalizar el tiempo completo de exposición, las larvas se retiran de la exposición a los distintos agentes químicos y fueron colocadas en medio de cultivo normal previamente preparado, para que concluyeran su ciclo de vida; la eclosión ocurrió de tres a cinco días después, y se procedió al análisis microscópico en organismos adultos.

\section{Análisis microscópico de ojos}

La evaluación del efecto genotóxico se realizó en los ojos de organismos adultos con el fenotipo White sobre contexto silvestre, registrándose el tamaño y frecuencia de éstos, para ello, los adultos recién eclosionados (máximo de 48 horas de edad), se sacrificaron con éter, posteriormente se separaron machos $\mathrm{y}$ hembras heterocigas (w+/w) (hembras de color rojo); con ayuda de un microscopio estereoscópico con un lente auxiliar $4 \mathrm{X}$, sumergiendo a las moscas en una solución anti reflejante (nueve partes de etanol al $70 \%$, disueltas en agua destilada y una parte de tween 80), con la finalidad de conservar hidratado el ojo y poder observarlos de una mejor manera, además de que al sumergirlas en dicha solución se disminuye la difracción de la luz. Evaluando el número y tamaño de clones celulares en ojo (Figura 3), analizando como mínimo las superficie de 500 ojos por concentración de acuerdo a lo establecido por Graf y colaboradores en 1984 sobre la técnica SMART "Somatic Mutation and Recombination Test" en donde se contabilizó la frecuencia de manchas (el número de repeticiones) y se clasificaron por su tamaño, en "chicas y grandes" (tipo), las chicas tienen de 2 a 4 omatidias afectadas mientras que las grandes tienen más de cuatro (Gaytán, 2006; Ayar y Uysal, 2013).
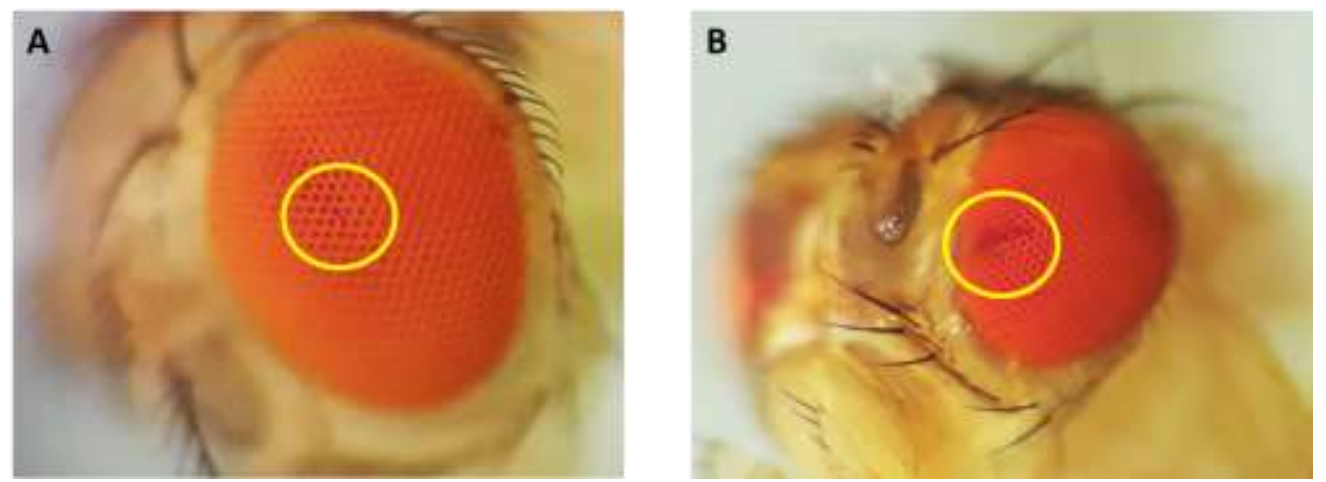

Figura 3. Manchas en ojo Drosophila melanogaster. A) Mancha chica, B) Mancha grande

\section{RESULTADOS Y DISCUSIÓN}

En la tabla I se observa los resultados obtenidos con el control positivo (O-Toluidina $2 \mathrm{mM}$ ); el cual produce un efecto positivo en manchas chicas y totales, como se esperaba por ser mutágeno de referencia, como agente carcinógeno de acción directa (Pratesi, 2003). 
Tabla 1. Número y porcentaje de manchas/ojo en el tratamiento en la técnica SMART ojo con OToluidina $[2 \mathrm{mM}]$.

\begin{tabular}{|lclll|}
\hline Control & & $\begin{array}{l}\text { Manchas } \\
\text { Chicas } \\
(1-3 \text { Cel. })\end{array}$ & $\begin{array}{l}\text { Grandes } \\
(>4 \text { Cel. })\end{array}$ & Totales \\
\hline Sacarosa & $5 \%$ & 15 & 10 & 25 \\
\hline O-Toluidina & $2 \mathrm{mM}$ & $66(+)$ & $32(+)$ & $98(+)$ \\
\hline
\end{tabular}

Diagnostico estadístico de acuerdo a Frei y Wurgler (1988)

$\mathrm{p}=<0.05$, positivo (+), negativo (-), débil positivo (d+) (citado Ayar y Uysal, 2013).

En el caso del extracto etanólico de té verde, a las concentraciones $12.5 \%, 25 \%$ y $50 \%$, estableciéndose la ultima como la $\mathrm{LD}_{50}$, los resultados indican que se produce un efecto negativo en manchas chicas, grandes y totales, debido a que tiene un efecto menor en comparación al control negativo (Tabla II y Figura 4).

En cuanto al tratamiento preventivo de manera previa (Tabla III). (antimutágeno) empleando el extracto etanólico de té verde a las diferentes diluciones (12.5\%, $25 \%$ y $50 \%$ ), previo a la aplicación del mutágeno de referencia (O-Toluidina, $2 \mathrm{mM}$ ), se observó un efecto positivo en la reducción de manchas chicas, grandes y totales; entendiéndose como un efecto protector del extracto de té verde ante el mutágeno al ser tratadas las moscas con té verde

Tabla 2. Número y porcentaje de manchas/ojo en el tratamiento con extracto etanólico de té verde $(12.5 \%, 25 \%$ y $50 \%)$.

\begin{tabular}{|lcccc|}
\hline \multicolumn{1}{|c}{ Control } & $\begin{array}{c}\text { Chicas } \\
(1-3 \text { Cel. })\end{array}$ & $\begin{array}{c}\text { Manchas } \\
(>4 \text { Cel. })\end{array}$ & Totales \\
\hline Sacarosa & $5 \%$ & 15 & 10 & 25 \\
\hline Té verde $12.5 \%$ & $5(-)$ & $11(-)$ & $16(-)$ \\
Té verde & $25 \%$ & $10(-)$ & $3(-)$ & $13(-)$ \\
Té verde & $50 \%$ & $5(-)$ & $4(-)$ & $9(-)$ \\
\hline
\end{tabular}

Diagnostico estadístico de acuerdo a Frei y Wurgler (1988)

$\mathrm{p}=<0.05$, positivo $(+)$, negativo $(-)$, débil positivo $(\mathrm{d}+)$. 


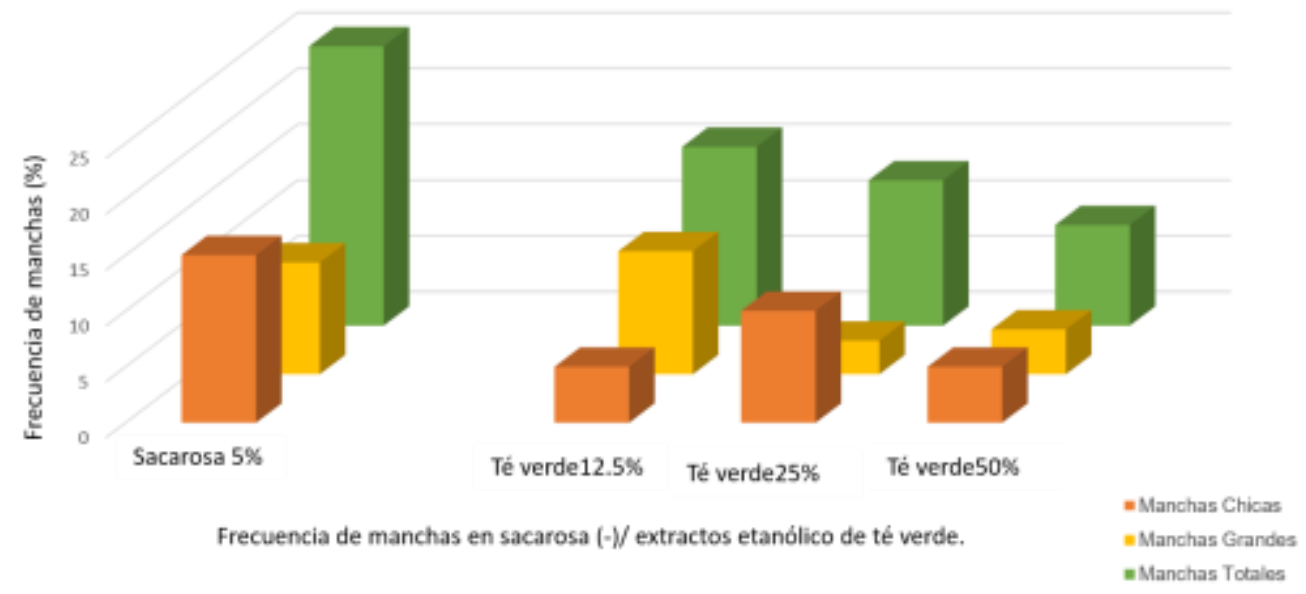

Figura 4. Distribución de manchas/ojo en el tratamiento alimenticio con control negativo (sacarosa al $5 \%$ ) y concentraciones de extractos etanólicos de té verde $(12.5 \%, 25 \%$ y $50 \%)$.

Tabla 3. Número y porcentaje de manchas/ojo en el tratamiento antimutagénico con extracto etanólico de té verde $(12.5 \%, 25 \%$ y $50 \%)$ y O-Toluidina $(2 \mathrm{mM})$.

\begin{tabular}{|c|c|c|c|}
\hline \multirow[b]{2}{*}{ Control } & \multicolumn{3}{|c|}{ Manchas } \\
\hline & $\begin{array}{l}\text { Chicas } \\
\text { (1-3 Cel.) }\end{array}$ & $\begin{array}{l}\text { Grandes } \\
(>4 \text { Cel. })\end{array}$ & Totales \\
\hline O-Toluidina $2 \mathrm{mM}$ & 66 & 32 & 98 \\
\hline té verde $12.5 \%+\mathrm{O}-\mathrm{T} 2 \mathrm{mM}$ & $8(-)$ & $9(-)$ & $17(-)$ \\
\hline té verde $25 \%+\mathrm{O}-\mathrm{T} 2 \mathrm{mM}$ & $3(-)$ & $3(-)$ & $6(-)$ \\
\hline té verde $50 \%$ & $2(-)$ & $1(-)$ & $3(-)$ \\
\hline
\end{tabular}

Diagnostico estadístico de acuerdo a Frei y Wurgler (1988)

$\mathrm{p}=<0.05$, positivo $(+)$, negativo $(-)$, débil positivo $(\mathrm{d}+)$.

Finalmente lo anterior se comparó con tres concentraciones de O-Toluidna $(0.5 \mathrm{mM}, 1 \mathrm{mM}$ y $2 \mathrm{Mm}$ ) lo cual se reforzó con el análisis de medianas, que mostró que existen diferencias significativas en la cantidad de manchas pequeñas, por lo cual se determinó que hay a mayor concentración mayor efectos antimutagénico $(\chi 2$ 6.66, gl: $3, \mathrm{p}<0.05 ; \mathrm{H}(3,12)$ : 9.15, $\mathrm{p}=0.027$ ), grandes $\left(\chi^{2} 6.67\right.$, gl: $3, \mathrm{p}<0.05$; $\mathrm{H}(3,12): 8.08, \mathrm{p}=0.045)$ y totales $(\chi 26.67, \mathrm{gl}: 3$, $\mathrm{p}<0.05 ; \mathrm{H}(3,12): 9.15, \mathrm{p}=0.027)$ entre tratamientos (Figura 5) 

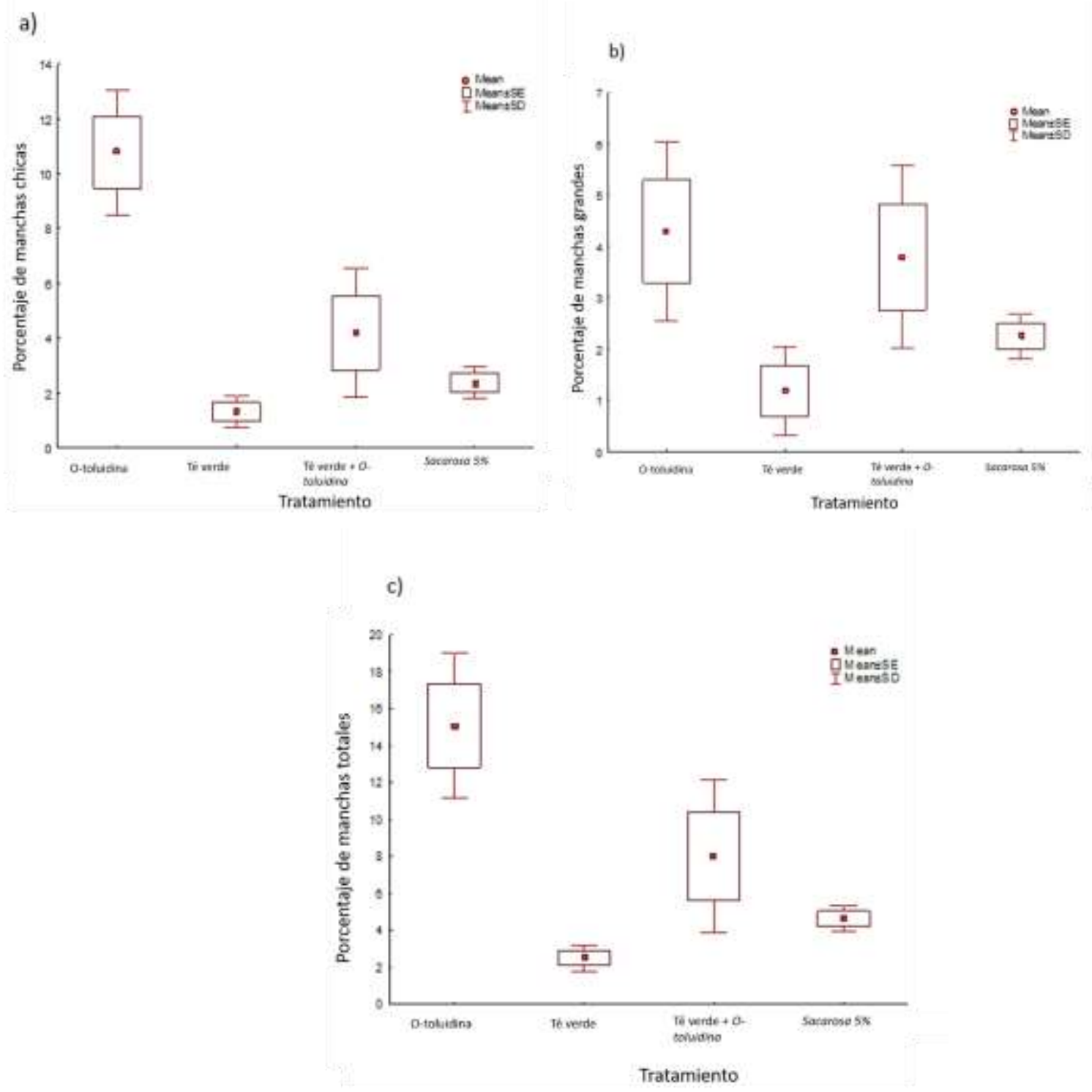

Figura 5. Comparación no paramétrica para muestras múltiples independientes entre manchas chicas (a), grandes (b) y totales (c), de los diferentes tratamientos evaluados.

\section{CONCLUSIONES}

El tratamiento mutagénico utilizando sólo el té verde, mostró una menor frecuencia en manchas pequeñas, grandes y totales, que las expresadas con el control negativo (sacarosa al 5\%), lo cual permite aseverar que su capacidad antioxidante del té verde es capaz de inhibir errores espontáneos que se expresan de manera natural. Como segunda conclusión en el presente trabajo, se pudo observar que la mezcla de té verde en sus diversas diluciones con la concentraciones de $2 \mathrm{mM}$ del mutágeno de referencia (O-Toluidina) mostró un efecto reductor en la frecuencia de daño estadísticamente positivo, que incluso fue más bajo que la frecuencia espontanea, determinado a través del control negativo, observándose una relación dosis- respuesta entre la capacidad de reducción de mutaciones con la concentración del extracto de té verde.

Por otra parte también se puede concluir que el mecanismo de acción del efecto antimutagénico 
está relacionado con la actividad antioxidante, los cuales también accionan después que el compuesto (mutágeno de referencia) metabolizó en el organismo. En general, los resultados sugieren que los extractos de té verde evaluados, tienen propiedades biológicas con un potencial benéfico para la salud humana y que se pueden utilizar en tratamientos preventivos contra el cáncer o como protección contra la exposición de mutágenos en ambientes laboral o naturales.

\section{LITERATURA CITADA}

Ayar, A. y Uysal, H. 2013. Genotoxic and safety assessment of parabens in somatic cells of in vivo Drosophila melanogaster. Turkish Journal of Biology, 37:683-688. https://doi.org/10.3906/biy-1303-60

Figueroa, V. y Lama, J. 2002. Las plantas de nuestro huerto. Tomo I. La Habana: Editorial Proyecto comunitario: Conservación de alimentos Habana, 22 pp.

García, V. 2008. Prácticas y conocimientos tradicionales del componente agrícola en las reservas naturales de la sociedad civil de la Cocha, Nariño. Trabajo de Grado. Instituto de Biología, Facultad de Ciencias Exactas y Naturales, Universidad de Antioquia. Medellín (Antioquia), Colombia. 1-11p.

Gaur, S. y Agnihotri, R. 2013. Green tea: A novel functional food for the oral health of older adults. Geriatrics Gerontol Int, 14: 238-250. https://doi.org/10.1111/ggi.12194
Gaytán, J. 2006. Evaluación ecotoxicológica del estradiol y sus metabolitos primarios liberados en el ambiente, a través de la actividad ganadera (tesis doctoral). México. UAEH. 85 pp.

Gee, J. M. y Johnson, I. 2001. Polyphenolic compounds: Interactions with the gut and implications for human health. Current Medicinal Chemistry, 8:1245-55. https://doi.org/10.2174/092986701337225 6

Martí, A., Moreno-Aliaga, M. J., Heberbrand, J. y Martínez, J.A. 2004: Genes, lifestyles and obesity. Int J Obes Relat Metab Disord, 28(3):29-36. https://doi.org/10.1038/sj.ijo.0802808

Muñoz-Velazquez, E. E., Rivas-Diaz, K., LoarcaPiña., F, Mendoza-Díaz., S, ReynosoCamacho., R. y Ramos-Gómez, M. 2012. Comparación del contenido fenólico, capacidad antioxidante y actividad antiinflamatoria de infusiones herbales comerciales. Revista Mexicana de Ciencias Agrícolas, 3 (3): 481-495. https://doi.org/10.29312/remexca.v3i3.144 3

Núñez, A. 2011. Terapia antioxidante, estrés oxidativo y productos antioxidantes: retos y oportunidades. Rev Cubana Salud Pública. 37: 644-60.

Patthamakanokporn, O., Puwastien, P. y Nitithamyong, A. 2008. Antioxidant activity and total phenolic compounds during storage of selected fruits. J. Food Composition Analysis, 21:241-8. https://doi.org/10.1016/j.jfca.2007.10.002

Pratesi, G., Bartolini, P., Senatra, D., Ricci, M., Righini, R., Barocchi, F. y Torre, R. 2003. Experimental studies of the orthotoluidine glass transition. Physical Review E, 67pp. https://doi.org/10.1103/PhysRevE.67.0215 05 
Copyright (c) 2019 Alejandra Sarahi Hern' ández-L ozada, Juan Carlos Gaytán-Oyarzún, Maritza López-Herrera, Pablo Octavio Aguilar, Fabiola Guzmán Ortiz

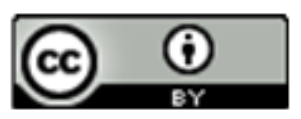

Este tex to está protegido por una licencia licencia CreativeCommons 4.0.

Usted es libre para Compartir — copiar y redistribuir el m aterial en cualquier medio o formato-y Adaptar el documento — remezclar, transformar y crear a partir del material- para cualquier propósito, incluso para fines com erciales, siempre que cumpla la condición de:

Atribución: Usted debe dar crédito a la obra original de manera adecuada, proporcionar un enlace a la licencia, e in dicar si se han realizado cambios. Puede hacerlo en cualquier forma razonable, pero no de forma tal que sugiera que tiene el apoyo del licenciante o lo recibe por el uso que hace de la obra.

Resumendelicencia - Textocompletodelalicencia 